\title{
Designing digital learning environments
}

\author{
Paul A. Jansen, Petra Fisser, and Cees Terlouw \\ SLO, The Netherlands. \\ P.Jansen@slo.nl \\ University of Twente, P.O. Box 217, 7500 AE Enschede, The Netherlands. \\ p.h.g.fisser@edte.utwente.nl,c.terlouw@oc.utwente.nl
}

\begin{abstract}
In this paper an overview is given of current developments in the Netherlands. The second part starts with some educational fundaments for Digital Learning Environments (DLE's). The elements of DLE's are described by the different interactions and communications between the student and participants and materials in learning environments. The paper finishes with some concrete examples and some considerations about choices to make for schools.
\end{abstract}

Keywords: Learning environments, flexible learning, innovation, policy

\section{INTRODUCTION}

Starting in 1998 there will be substantial investment in the use of ICT in Dutch schools. One of the major programs from the Dutch government "Investeren in Voorsprong" ("Investing in Progress") was launched in 1997. This program was a strongly governmental steered implementation plan, which aimed at the integration of ICT in education in such a way that it contributes to the actuality, quality, effectiveness and attractiveness of education (Ministry of Education, Culture and Science, 1997). The plan was would eventually result in a ratio of one computer for every ten children.

In April 1999 the new Minister of Education presented the continuation of "Investing in Progress" in the program "Onderwijs online, verbindingen naar de toekomst" ("Education online, connections to the future"). In that plan the responsibility for the implementation of ICT in education is put in

The original version of this chapter was revised: The copyright line was incorrect. This has been corrected. The Erratum to this chapter is available at DOI: 10.1007/978-0-387-35403-3_29 
the hands of the schools themselves. Schools receive a fixed sum per pupil from the Ministry which is intended to incorporate new media into their curricula. They can decide for themselves how they will make use of this budget for hardware, software and training, while the government only determines the overall policy, promotes relevant training for teachers and encourages the development of methodology and software. One part of the national programs is to encourage all primary and secondary teachers to get their 'Digital Driving License for Education', in order to obtain skills and knowledge in several ICT applications.

Another part of these governmental plans is to provide all ca. 10.000 Dutch schools (vocational tertiary, secondary and primary) with a special extranet, called "kennisnet" ("knowledge-net"). The goal of this project is to connect groups (students, teachers, parents, schools, organisations and other interested parties) with each other, with educational suppliers and with Internet. This plan has to be carried out before the end of 2001 .

Giving schools money and a connection to the Internet will not provide a good learning environment for a student. Embedding ICT in education requires more than that, including a didactical way of integrating ICT in education in such a way that ICT supports the learning environment of the student. The questions we want to answer in this paper are twofold:

1. Which is the framework in which a powerful didactical concept is combined with an ICT-approach?

2. Which real existing Digital Learning Environments (DLE) are present in

Dutch primary and secondary education which illustrate and elaborate the framework?

We will illustrate our approach with examples of DLE's for Dutch primary and secondary schools. Finally, we will conclude with some points of discussion.

\section{THE OVERALL DIDACTICAL FRAMEWORK}

Nowadays the continuum teacher-centred $<->$ student-centred ${ }^{3}$ education is an important perspective to consider. The teacher-centred end of the continuum concerns the activities of the teacher in order to stimulate learning of students. The other end of the continuum concerns the own, selfdirected activities of students in order to learn.

In general the trend is to move from a more teacher-centred approach to a more student-centred approach in the target situation. Therefore, two types of didactical approaches are distinguished, both examples of metacognitive

\footnotetext{
${ }^{3}$ The term "students" includes pupils in primary and secondary education.
} 
skills that are needed in order to find the relevant information: (a) selfdirected learning in which students create their own learning process, and (b) scaffolding, in which students realise their learning process with decreasing help of teachers. This distinction is also relevant in education in which ICT is involved.

Scaffolding is, as said, a didactical approach in which the metacognitive skills can be learned. Scaffolding can be described as a communication process in which support, given by the teacher, gradually decreases. It is a process of gradual reduction of support until the scaffolding is no longer needed. (Jonassen, 1996; King, Staffieri, \& Adelgais, 1998; Winnips, 1998). The instructor monitors student learning in a careful and individualised way and withdraws support when the student can work on his or her own (Collis, Winnips \& Moonen, 1999). In figure 1 the process of scaffolding is represented.

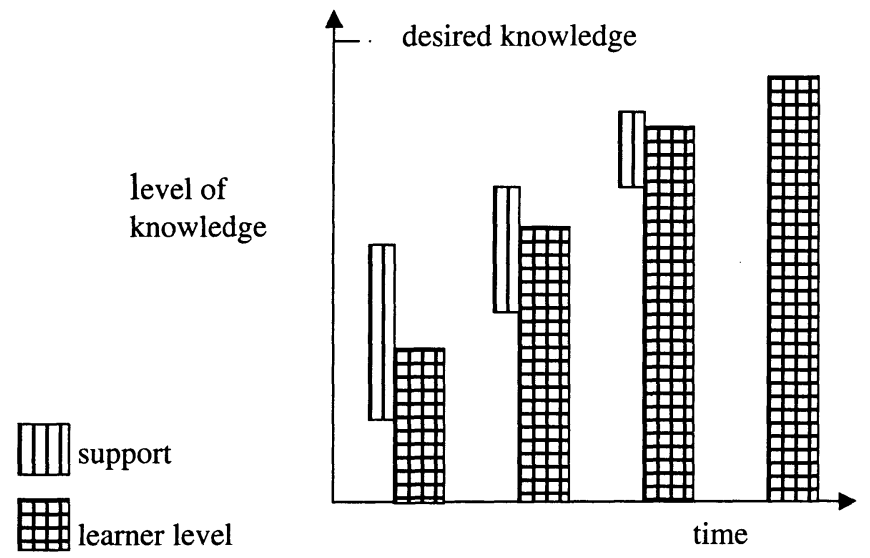

Figure 1. The process of scaffolding (adapted from Winnips, 1998)

The ideas described above follow the constructivist learning approach. The constructivist approach has been described by many authors. We would like to follow Tabbert's description that learning is a process of knowledge construction, learning occurs by interpreting information, people use current knowledge to construct new knowledge and learning is highly adjusted to the situation in which it takes place (Tabbert, 1993). In other words, in this approach knowledge is believed to be actively constructed, tightly connected to the individual's cognitive repertoire and to the context within this activity takes place.

According to Salomon (1998) ICT offers the opportunity of actively constructing knowledge in particular symbolic forms (word, graph, pictures) and structured in particular organisational ways (databases, hypermedia) 
available for exploration and manipulation. Salomon further claims that not just being exposed to these symbol systems of technology and media, but being actively involved in construction, either individually or collaboratively, makes this possibility a powerful one. Salomon's ideas offer a first handgrip in answering the question of how to combine ICT and a good didactical concept to result in an effective DLE. In the following sections of this paper we will elaborate on this.

\section{A FRAMEWORK FOR ICT AND INTERACTION}

We will start by giving a frame of reference with regard to ICT in education, focussing on the interactions that are needed in education and can be made possible by using ICT.

\subsection{A model for interaction}

Communication can be seen as a certain amount of interactions that a student can have with its environment. Sysling and Van Veen (1997) have outlined a model in which the student, according to the latest principles of the before mentioned learning theories of constructivism, is the central person in a learning process. The student has different kind of interactions with his environment. This is shown in Figure 2.

In this model the student is the most important person in a learning process. According to Sysling and Van Veen the student has several possibilities to start an interaction with his environment: he can study learning materials, receive assignments from the teacher, look for information in a library, discuss the material with fellow students, etc. In return, the environment can have interactions with the student: the teacher gives instructions and feedback, students work together on an assignment, the organisation keeps track of study progress, etc. All these interactions can be categorised with the before mentioned distinctive didactical approaches: self-directed learning and scaffolding.

Sysling and Van Veen claim that for each interaction ICT can be used. They also claim that this kind of education, in which the student is the central focus point and in which ICT is integrated in education, leads to DLE's, with sufficient possibilities for interaction and for real learning. 


\author{
teacher \\ (at school or external)
}

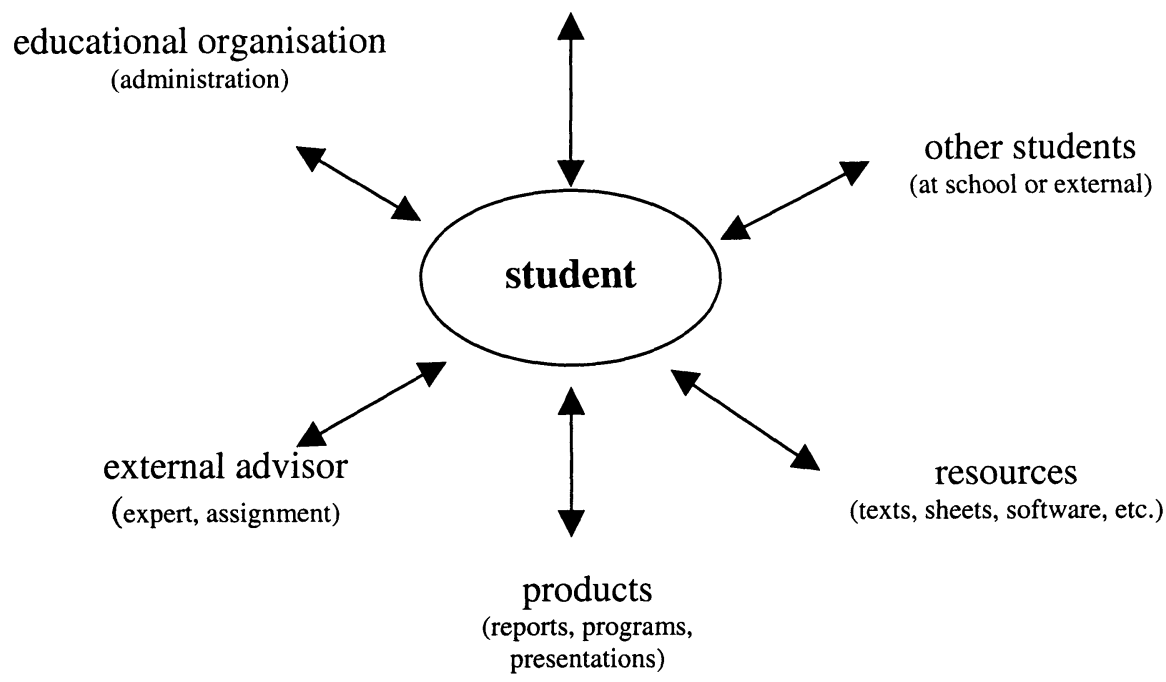

Figure 2. Interactions between student and learning environment (adapted from Sysling and van Veen (1997)

\title{
3.2 A digital learning environment
}

Against this background, we argue that by combining the communication possibilities of ICT and a constructivist didactical framework with effective interactions a Digital Learning Environment (DLE) can be created. A traditional learning environment of a student consists of a combination of means, strategies, persons and facilities to place a student in a position in which he or she can learn. A DLE supports and enriches the traditional environment by functionally using ICT.

Mirande, Riemersma and Veen (1997) give a broad definition of a DLE: each learning environment that uses technology. In the context of DLE's Collis (1996) speaks about telelearning and defines telelearning as "making connections among persons and resources through communication technologies for learning-related purposes". This means that the learner is engaged in learning, but not on his own. The learner makes connections with others (teacher, other students, etc.) or with specific resources (text, video, etc.). According to Collis the persons and resources involved in telelearning may be beyond what the learner could have access to in his ordinary learning context, but they may be also the same persons and resources, made accessible in different ways and at different times than before. 


\section{METHOD}

In order to answer the second research question about real existing DLE's which are present in Dutch primary and secondary education, literature and WWW research has been conducted. Looking at the given framework and the description of DLE's the first step is to describe existing examples of ICT in education and the interactions as mentioned in the model in Figure 2.

We will follow the argumentation of Sysling and Van Veen in relation to interactions and the description of Collis of Telelearning or DLE's and describe each category of interaction with examples from teaching practice.

\section{RESULTS}

Before we discuss each interaction we will answer the question if interaction via ICT can be used for pupils from primary and secondary schools. We will give a short view on the situation in these schools.

\subsection{Current situation}

Each year the Research Centre of the University of Twente produces an ICT-monitor. The ICT-monitor reports on the current state-of-affairs of ICT in Dutch education. The latest ICT-monitor (Brummelhuis, 1998) shows that the attitude in primary education towards the educational use of ICT has changed positively over the years. Many teachers are convinced that ICT is useful for education. A third of the teachers find themselves insufficiently informed about the possibilities. Since one cannot implement ICT-practices that one doesn't know, it is expected that the implementation will stagnate in an increasing number of schools. The ICT-monitor for secondary education shows that teachers think they will no longer be the most important source of information. Computers are seen as an important tool for the organisation of the education. Students use computers independently working on assignments or searching for information. Computers will be available to them, just as any other learning material. Although the willingness to change is large and the use of ICT is seen as valuable and relevant, most teachers think they lack relevant information and haven't got enough materials.

By this we see that ICT is a hot topic at both the primary and secondary schools. Although several problems have been observed (especially related to teacher training) there are many possibilities for ICT at these schools. We will describe some possibilities in the next paragraphs, relating to the interactions of a student as described in the theoretical framework. 


\subsection{Student-teacher interaction}

Giving assignments, discussions between teachers and students and giving feedback on assignments are examples of student-teacher interaction, where scaffolding is crucial. One of the most common ways to use ICT for this kind of interaction is e-mail. Students can ask questions about the learning material, teachers can supply information about the course and give feedback, etc. This kind of interaction can also be supported by using the Internet. Usually this is done by providing general course information, such as information about the goals, the schedule of lectures and information about teachers and students.

Examples of the use of e-mail at primary and secondary schools can be found, but it usually concerns communication between students. Examples of e-mail communication between teachers and students are barely found. One example is the project 'Kid E-mail' where students and teachers used email in an organised way to exchange ideas about flying constructions.

A more technological enhanced tool for student-teacher interaction is video- or audio conferencing. With the help of these technologies a teacher can reach a student at a remote site. This is often used if a student cannot come to class easily. These technologies will be used more often, when the infrastructure will be available at the schools.

\subsection{Student-student interaction}

An example of student to student interaction in a learning process is communication during an assignment. Tasks have to be divided and a product has to be made. Using e-mail and a website as described above for interaction between teacher and student can be used in the same way for interaction between students. Communication with other students in another country is one of the possibilities.

An example of this type is the project " Stuyvesant and Dutch Colonies in the U.S." in which a Dutch primary school and an American Middle School study together (see www.gco.nl/tyr/menue.htm). The project has started by making acquaintance by mail. The educational department in the municipality of the Dutch school provides a lot of information about the period in which Stuyvesant lived. The students from the Netherlands and the USA were matching their results which are published at the website.

Another way for student to student interaction is to put their assignment or product on the web. This can be a simple webpage with information or a more sophisticated digital portfolio. Examples of this on the Internet are drawings of children that are scanned and put on a webpage or a digital school newspaper with short stories or children's songs. 
There are more advanced tools for collaboration, such as discussion lists on the Internet or GroupWare. The amount of examples to be found of this kind of collaboration at primary and secondary schools is rising. This is inherent to the way primary and secondary education is organised and to the level of ICT skills of the students. Next to this we believe that the growing use of tools as GroupWare is one of the results of teacher training.

\section{$5.4 \quad$ Student-resources interaction}

One of the major advantages of the Internet is the huge amount of information that can be found. There is information about an enormous diversity of subjects. Not all information is well structured or easy to find. This means that students have to learn new skills in retrieving and managing the information. These skills are included in the Dutch curricula.

It is not possible to give an extensive and comprehensive list of all kinds of examples of student-resources interactions. It is sufficient to say that there are many possibilities (searching on the WWW for a specific subject, etc.). The pitfall is the overload of information and the necessary skills to discriminate between useful and second-rate information.

\subsection{Student-product interaction}

Student-product interaction differs from student-resources interaction. In the latter the retrieval of information is the key issue. In student-product interaction the issue is to use the found information and make an own product. This can be done individually or with fellow students. Again, email, a website and GroupWare can be used to facilitate this process. Working together on a document, developing a homepage or making a presentation or portfolio are all examples of student-product interaction.

\subsection{Student-external advisor interaction}

One of the possibilities of ICT is to bring an external expert in the classroom. This can be a veterinarian telling something about horses by videoconferencing, asking questions by e-mail to a historian about the Middle Ages, or an artist showing his latest paintings on his homepage. The expert delivers the content and the students can listen and ask questions. An example of this can be found at a website made for primary schools (www.iselinge.nl/Scholenplein/euro/index.htm). One of the course ideas on this site is offering students the possibility to ask questions to people who know a lot about the Euro, for instance banks, Ministries of Finance, etc. 


\subsection{Student-organisation interaction}

It is important for a school to keep track of the learning results of the students. There are several ways of doing this. Common tools are word processors and spreadsheets to save the data. There are more sophisticated tools to keep track of the learning results. One of them is a new developed tool called SPRS, a Study Planning and Registration System which offers a digital platform for contents, planning, assessment and registration.

\section{INTEGRATING INTERACTIONS INTO A DLE}

As we have seen, there are many possibilities for using ICT for interactions in education. But it is also clear that the interactions as described above are all a specific part of the learning process. Integrating all kind of interactions with particular ICT tools and applications into one environment which is accessible for students and teachers is what every school should aim for if it wants to use ICT effectively.

At this moment there are some examples present in the Netherlands of primary and secondary schools that use such an environment. Discussions are going on about the installation of such platforms in a region, using for example the infrastructure of the university in this region. Therefore it is interesting to look at some examples from Higher Education, because it looks to be a real future for primary and secondary education.

\subsection{Existing DLE-platforms}

There are several commercial products that can be used to offer a DLE. Recently a research is carried out in the Netherlands in which several commercial products are compared for use in Higher Education (Droste, 1999). As a conclusion, Droste argues that strategic attention has to be paid to the situation in which a platform is used, to the support of specific functionalities in the platform, to the support from the organisation for purchase such a platform, to technical and maintenance issues and last but not least to the costs of such a platform (Droste, pp. 39). We think that this conclusion is also true when choosing a platform for primary and secondary education. Next to this we argue that also the training of teachers is included when different platforms are considered.

Although there are platforms for DLE's available as shown above, there are several institutions that have developed their own platform or DLE. One could say that they are re-inventing the wheel, but some of these projects have good reasons for developing an own product. As an example we give a 
short overview of the DLE that is developed at the University of Twente, C@mpus+, a Learning Environment that will be used at secondary schools too in the future.

C@mpus+ started as a project of the Faculty of Educational Science and Technology as the TeLeTOP (Telelearning at TO) Project. TeLeTOP is focused on extending the Faculty's innovative technological profile through integrating telematics applications in our own courses for more-flexible learning. TeLeTOP is the implementation project that supports the Faculty's philosophy: Extending the benefits of good teaching and a good campusbased experience to all students: full-time students and part-time students who are not always at the campus. The part-time students can follow the courses at their home or workplace, but have to come to the university once every two weeks to follow lectures, in accordance with the Faculty's philosophy (for more information about the TeLeTOP project see the TeLeTOP homepage http://teletop.edte.utwente.nl/).

The Faculty of Educational Science and Technology choose to develop its own system, after evaluating other existing systems. All existing products had good aspects, but none of them supported the Faculty's philosophy to the extend that was wanted. The TeLeTOP project was carefully evaluated and based on the results of this evaluation the university decided that this system should be used throughout all Faculties of the university. In 2000 several Faculties will start to use the TeLeTOP system, now called C@mpus+, probably including a group of secondary schools in the region.

\subsection{Considerations for DLE's at schools}

The constructivist approach offers many starting points for a good didactical foundation for making useful usage of ICT in education. With ICT the learner can construct his or her own knowledge in co-operation contexts. As we have seen in the description of the interactions that a student can have with the environment, with ICT knowledge can be constructed through communication with teachers and fellow students. The teacher is still needed in this process, especially at the beginning of the learning process. A student has to learn how to construct his own knowledge. He has to learn how to retrieve the right information and he has to learn how to interpret and deal with the found information. But gradually the teacher's role will change from telling the student what he should do to supporting (coaching) the student in his learning process.

A good DLE provides possibilities for all interactions described by Sysling and Van Veen (1997). These interactions model the learning environment that is needed for a student to gain the necessary knowledge, skills and attitudes. The level of use of ICT for these interactions will depend 
on both the teacher and the student. The student should have the possibility to use ICT when useful. The necessary skills to use ICT should be acquired in order to use ICT as effectively as possible and face-to-face communication remains important. Both students and teachers have to obtain the necessary skills to use ICT in education. Teachers indicate that they need more knowledge and training in the pedagogical, didactical en organisational aspects of computer use in education (Brummelhuis, 1998).

The support of the government is important. Overall policy should be developed with attention for didactical methodology. Training for teachers should be available to all schools. Next to this the support of the management and the teachers of the schools is important. From the Dutch ICT-monitor it seems that the overall opinion is positive. This is important for the success of the implementation of ICT at schools.

In conclusion, a DLE should correspond with the views of the school towards education and the place ICT will take within it. A school should use ICT not only to the norms of society, but also to educational norms and values. Enough attention should be paid to the appropriateness of using ICT. Some situations are more appropriate then others. All kind of interactions should be imaginable, where possible supported by ICT. When used well, ICT can help a student to become a self-directing, flexible, communicative member of society.

\section{REFERENCES}

Brummelhuis A. (1998a) ICT-monitor 1997/1998, Basisonderwijs en Voortgezet Onderwijs [primary and secondary education], Enschede, Universiteit Twente, Onderzoek Centrum Toegepaste Onderwijskunde (OCTO).

Collis, B. (1996) Tele-learning in a digital world. The future of distance learning, International Thomson Computer Press, London.

Collis, B., Winnips, J., and Moonen, J. (1999) Scaffolding and the use of the WWW: Does it pay off?, Manuscript submitted for publication to the Journal of Interactive Learning Research).

Droste, J. (1999) Advies keuze teleleerplatform, Stichting SURF, Utrecht.

Jonassen, D. (1996) Scaffolding diagnostic reasoning in case-based-learning environments, Journal of Computing in Higher Education, 8(1), 48-68.

King, A., Staffieri, A., and Adelgais, A. (1998) Mutual peer tutoring: Effects of structuring tutorial interaction to scaffold peer learning, Journal of Educational Psychology, 90(1).

Ministry of Education, Culture and Science. (1997) Actieplan and Implementatieplan voor Informatie-en CommunicatieTechnologie in het onderwijs [Action plan and Implementation plan for Information and Communication Technology in education], OCenW, Zoetermeer

Mirande, M., Riemersma, J., and Veen, W. (1997) De digitale leeromgeving [The digital learning environment], Wolters Noordhoff, Groningen. 
Salomon, G. (1998) Novel constructivist learning environments and novel technologies: Some issues to be concerned with, Research Dialogue in Learning and Instruction, 1(1).

Sysling, M., and Van Veen, B. (1997) Inventarisatie Teleleren CT\&M [Inventory Telelearning Civil Engineering and Management, DOC 98-04], Educational Centre, University of Twente, Enschede.

Tabbert, B. (1993) Allan Collins, From inquiry teaching to cognitive apprenticeship, In Instructietheorie (eds. S. Dijkstra, T. Dillingh, and B. Tabbert), 2, p. 97-147.

Winnips, J. (1998) Scaffolding van ontwerpvaardigheden voor het ontwerproces van onderwijskundige media door middel van gehyperlinkte ULMs [Scaffolding the development of skills in the design process for educational media through hyperlinked units of learning material (ULMs)], Internal report, Faculteit der Toegepaste Onderwijskunde, Universiteit Twente.

Winnips, J., and Collis, B. (1999) Examples of scaffolding in the practice of tele-learning environments, Presentation and panel session at EDMEDIA '99, Seattle.

\section{BIOGRAPHIES}

Paul Jansen graduated in 1973 in mathematics. He became and had several functions in school management. In 1989 he joined the SLO, the Dutch National Institute for Curriculum Development. 'He has been project leader and co-ordinator for many projects involving ICT as a subject and integrated in other subjects. Since 1999 he is director of 'the School of the Future', an institute specialised in renewing education and business by ICT.

Petra Fisser is a scientific staff member at the University of Twente, Faculty of Educational Science and Technology, department of Educational Instrumentation. Her research focuses on the factors that stimulate using ICT in education and especially for the university.

Cees Terlouw graduated in 1976 in Educational Sciences at the Dutch University of Groningen, and received his Ph.D in 1987 at the University of Twente on an empirical study on instructional design for problem solving in social sciences. He works at the University of Twente, from 1987 at the Educational Center on topics such as problem solving, course development, teacher training and use of ICT in secondary and higher education. Since 1999 the Educational Center is a part of the Dinkel-institute, where he is a member of the management. 